\title{
Structural Credit Risk Models with Subordinated Processes
}

\author{
Martin Gurny, ${ }^{1,2}$ Sergio Ortobelli Lozza, ${ }^{1,3}$ and Rosella Giacometti ${ }^{1}$ \\ ${ }^{1}$ Department of Management, Economics and Quantitative Methods, University of Bergamo, Via dei Caniana 2, \\ 24127 Bergamo, Italy \\ ${ }^{2}$ Department of Applied Finance and Actuarial Studies, Macquarie University, Eastern Road, North Ryde, NSW 2109, Australia \\ ${ }^{3}$ Department of Finance, Faculty of Economics, VŠB-Technical University of Ostrava, Sokolská 33, 70121 Ostrava, Czech Republic
}

Correspondence should be addressed to Sergio Ortobelli Lozza; sol@unibg.it

Received 31 January 2013; Accepted 15 July 2013

Academic Editor: Xiaoning Zhang

Copyright (C) 2013 Martin Gurny et al. This is an open access article distributed under the Creative Commons Attribution License, which permits unrestricted use, distribution, and reproduction in any medium, provided the original work is properly cited.

\begin{abstract}
We discuss structural models based on Merton's framework. First, we observe that the classical assumptions of the Merton model are generally rejected. Secondly, we implement a structural credit risk model based on stable non-Gaussian processes as a representative of subordinated models in order to overcome some drawbacks of the Merton one. Finally, following the KMV-Merton estimation methodology, we propose an empirical comparison between the results obtained from the classical KMV-Merton model and the stable Paretian one. In particular, we suggest alternative parameter estimation for subordinated processes, and we optimize the performance for the stable Paretian model.
\end{abstract}

\section{Introduction}

Estimating a borrower's risk level, namely, the probability of default (PD), by assigning an appropriate PD is a widely employed strategy by many financial institutions as well as the supervisory authorities. PD indicates a probability that a given counterparty will not be able to meet its obligations. The incorrect estimation of PD leads to, among other things, unreasonable ratings and incorrect pricing of financial instruments, and thereby it is one of the causes of the recent global financial crisis. Undervaluation of the risk caused the collapse of the financial system which has been extended through credit derivatives on the global markets. PD is also a crucial parameter used in the calculation of economic or regulatory capital, under the Basel II and Basel III Accords for banking institutions. These reasons highlight how important the estimation of PD is and why it has been a significant research topic for a long time.

The probability of default, as one of the key risk parameters in the IRB approach, has many methodologies for its estimation. In general, we can classify the existing methodologies into three groups: structural models, reduced-form models, and credit-scoring (statistical) models. We will focus on the first type of models only in this paper. This structural approach was proposed in 1974 by Robert Merton [1] in his seminal paper on the valuation of corporate debt. Largely as a logical extension of the Black-Scholes [2] option pricing framework in 1973, he introduced a model for assessing the credit risk of a company by characterizing a company's equity as a derivative on its assets.

A number of researchers have examined the contribution of the Merton model over the past several years. An overview of structural credit risk models can be found in Bluhm et al. [3] and in Duffie and Singleton [4]. Practitioners employed by either Moody's or KMV were the first ones who analysed Merton model carefully. Moreover, the KMV default probability model is summarized by Crosbie and Bohn [5] Bohn et al. [6] argue that the KMV-Merton model captures all of the information in traditional agency ratings and wellknown accounting variables. The model's predictive power is examined, for instance, by Du and Suo [7] and Hillegeist et al. [8]. Duffie et al. [9] show that the KMV-Merton model probabilities have significant predictive power in modelling default probabilities over time. Farmen et al. [10] investigate default probabilities and their comparative statics in the Merton framework using objective probability measure. The main theoretical models of risky debt valuation built on Merton [1] and Black and Cox [11] are discussed in Bohn 
[12]. In the literature on bank deposit insurance, a contingent claim valuation of equity has been used extensively. In this case, the equity call model is reversed to generate estimates of the market value of assets from observed share prices. This approach allows for the calculation of fair deposit insurance premium. Duan [13] proposes another method for estimating asset value and volatility which is based on the maximum likelihood estimation using equity prices.

The Merton model requires a number of simplifying assumptions (the company can default only at debt's maturity time $T$ but not before; the model is not able to distinguish among the different types of debt, constant and flat term structure of interest rates, etc.). Notwithstanding, one of the most important drawbacks is an assumption that company value follows the log-normal distribution. It is well known that log-returns of equities are not Gaussian distributed, and several empirical investigations have shown that log-returns of equities present skew distributions with excess kurtosis which leads to a greater density in the tails, and that the normal distribution with a comparatively thinner tail simply cannot describe this phenomenon (see Mandelbrot [14-16], Fama [17-19], or Rachev and Mittnik [20]).

The main contribution of this paper is twofold. First, we introduce a structural credit risk model based on the stable Paretian distributions as a representative of subordinated models. Secondly, we show that it is possible to use this model in the Merton's framework, and we propose an empirical comparison of the KMV methodology applied to the Merton model and our subordinated one. In particular, we prove that the basic assumption of the Merton model is generally rejected, and thus the log-returns of the company's assets value are not Gaussian distributed. For this reason, we discuss the possibility for using other subordinated processes to approximate the behaviour of the log-returns of the company value. Thus, we propose to use the Hurst et al. [21] option pricing model based on the stable Paretian distributions which generalizes the standard Merton methodology.

The practical and theoretical appeal of the stable nonGaussian approach is given by its attractive properties that are almost the same as the normal ones. As a matter of fact, the Gaussian law is a particular stable Paretian one, and thus the stable Paretian model is a generalization of the Merton one. The first relevant desirable property of the stable distributional assumption is that stable distributions have domain of attraction. The generalized central limit theorem for the normalized sums of i.i.d. random variables determines the domain of attraction of each stable law. Therefore, any distribution in the domain of attraction of a specified stable distribution will have properties close to those of the stable distribution. Another attractive aspect of the stable Paretian assumption is the stability property; that is, stable distributions are stable with respect to summation of i.i.d. random stable variables. Hence, the stability governs the main properties of the underlying distribution. In addition, in the empirical financial literature, it is well documented that the asset returns have a distribution whose tail is heavier than that of the distributions with finite variance.

The idea of using subordinated stable Paretian processes goes back to the seminal work of Mandelbrot and Taylor
[22]. Stable laws have been applied in several financial sectors (see Rachev [23] and Rachev and Mittnik [20]). For these reasons, the stable Paretian law is the first candidate as a subordinated model investigating for credit risk modeling, and in this paper we discuss how to use the Hurst et al. [21] stable subordinated model in the framework of structural credit risk models. In particular, as for the Merton model, we propose two different methodologies for the parameter estimation: the first is to generalize the maximum likelihood parameter estimation proposed by Duan [13]; the second is a generalization of the KMV methodology.

This paper is organized as follows. In Section 2, we firstly review the theory and the distributional assumptions of the Merton model. Subsequently, we introduce the credit risk models with subordinated processes and describe the Mandelbrot-Taylor distributional assumptions. Section 3 is devoted to the parameters estimation for both the Merton and the subordinated models. We characterize empirical data and make a comparison between the obtained results in Section 4. Finally, in the last section, we provide a brief summary.

\section{Merton and Subordinated Credit Risk Models}

The core concept of the Merton model [1] introduced in 1974 is to treat company's equity and debt as a contingent claim written on company's assets value. In this framework, the company is considered to have a very simple capital structure. It is assumed that the company is financed by one type of equity with a market value $E_{t}$ at time $t$ and a zero-coupon debt instrument at $t\left(D_{t}\right)$ with a face value of $L$ maturing at time $T$. (Generally, in a credit risk models framework we assume one-year time horizon for debt maturity and subsequent estimation of PD. One year is perceived as being of sufficient length for a bank to raise additional capital on account of increase in portfolio credit risk (if any).) The exercise price of a call option is defined as the value $L$. Let $A_{t}$ be the company's asset value at time $t$. Naturally, the following accounting identity holds for every time point:

$$
A_{t}=E_{t}+D_{t}
$$

In the Merton framework the value of company's equity at maturity time $T$ is given by

$$
E_{T}=\max \left[A_{T}-L, 0\right] .
$$

2.1. The Merton-Black-Scholes Distributional Assumptions. Under the Merton model, the assets value is assumed to follow a geometric Brownian motion (GBM) in the following form:

$$
d A_{t}=\mu A_{t} d t+\sigma A_{t} d W_{t}
$$

where $\mu$ is the expected return (drift coefficient), $\sigma$ is the volatility (diffusion coefficient), both unobserved, and $W_{t}$ is 
the normal variable $N(0,1)$. Using Ito's lemma, we can obtain the solution of (3) as follows:

$$
A_{T}=A_{t} \exp \left[\left(\mu-\frac{1}{2} \sigma^{2}\right)(T-t)+\sigma \sqrt{(T-t)} W_{t}\right],
$$

where $(T-t)$ is a remaining maturity.

In accordance with the Black-Scholes option pricing theory [2], the Merton model stipulates that the company's equity value satisfies the following equation for pricing the call option within a risk neutral framework:

$$
E_{t}=A_{t} \Phi\left(d_{1}\right)-L e^{-r(T-t)} \Phi\left(d_{2}\right),
$$

where

$$
\begin{gathered}
d_{1}=\frac{\ln \left(A_{t} / L\right)+\left(r+(1 / 2) \sigma^{2}\right)(T-t)}{\sigma \sqrt{(T-t)}}, \\
d_{2}=d_{1}-\sigma \sqrt{(T-t)}
\end{gathered}
$$

$r$ is the risk-free interest rate and $\Phi(\cdot)$ is the cumulative distribution function of the standard normal variable. (The Treasury bill yields are commonly used as the risk-free interest rate $r$. Their rates are considered an important benchmark because treasury securities are back by the full faith and credit of the U.S. Treasury. Therefore, they represent the rate at which investment is considered risk-free.) Equation (7) is referred to as the distance-to-default (DD) by Moody's KMV. The larger the number in DD is, the less chance the company will default.

We can estimate PD by rearranging (4) as follows:

$$
\begin{aligned}
& \mathrm{PD}_{t}= P\left[A_{T} \leq L\right] \\
&=P\left[\ln \left(A_{t}\right)+\left(\mu-\frac{1}{2} \sigma^{2}\right)(T-t)\right. \\
&\left.\quad+\sigma \sqrt{(T-t)} W_{t} \leq \ln (L)\right] \\
&=\int_{-\infty}^{-\left(\ln \left(A_{t} / L\right)+\left(\mu-(1 / 2) \sigma^{2}\right)(T-t)\right) / \sigma \sqrt{(T-t)}} \phi(x) d x,
\end{aligned}
$$

where $\phi$ is the probability density function of a standard normal variable. Note that unlike (8), (5) is not a function of $\mu$, but it is a function of $r$ (we would get PD under the risk neutral probability measure). When we estimate $\mathrm{PD}$, the riskfree interest rate $r$ has to be replaced with real company drift $\mu$ since this step has nothing to do with option pricing. Thereby, the default probability of the company under the objective probability measure is given by

$$
\begin{aligned}
\mathrm{PD}_{t} & =\Phi\left(-\widehat{d}_{2}\right) \\
& =\Phi\left(-\frac{\ln \left(A_{t} / L\right)+\left(\mu-(1 / 2) \sigma^{2}\right)(T-t)}{\sigma \sqrt{(T-t)}}\right) .
\end{aligned}
$$

Further discussion on this topic can be found in Deliandes and Geske [24] who showed that risk neutral PDs can serve as an upper bound to objective PDs.
2.2. Credit Risk Models with Subordinated Assumptions. Using subordinated processes, we are usually able to capture empirically observed anomalies which are presented in the evolution of return processes over time. That is, we substitute the physical (calendar) time with a so-called intrinsic (operational) time which provides distribution tail effects often observed in the market (see Hurst et al. [21] and Rachev and Mittnik [20]). Thus, if $W=\{W(t), t \geq 0\}$ is a stochastic process and $T=\{T(t), t \geq 0\}$ is a nonnegative stochastic process defined on the same probability space and adapted to the same filtration, a new process $Z=$ $\{Z(t)=W(T(t)), t \geq 0\}$ may be formed, and it is defined as subordinated to $W$ by the intrinsic time process $T$. Next, we will suppose that $W$ is a standard Brownian motion. In this case, if the intrinsic time process $T$ is the deterministic physical time, that is, $T(t)=t$, we obtain the classical lognormal model (see Osborne [25]). Typically, subordinated models with random intrinsic time are leptokurtic with heavier tails compared to the normal distribution. Feller [26] showed that if the intrinsic time process has non-negative stationary independent increments, then the subordinated process $Z$ also has stationary independent increments.

Generally, we assume frictionless markets, where the logprice process $Z$ is subordinated to a standard Brownian motion $W$ by the independent intrinsic time process $T$. Therefore, we model the assets price process $A_{t}$ (the company's assets value in our case) by a stochastic equation of the type as follows:

$$
\begin{gathered}
A(t)=A\left(t_{0}\right) \exp \left\{\int_{t_{0}}^{t} \mu(s) d s+\int_{t_{0}}^{t} \rho(s) d T(s)\right. \\
\left.+\int_{t_{0}}^{t} \sigma(s) d W(T(s))\right\},
\end{gathered}
$$

where the drift in the physical time scale $\mu(s)$, the drift in the intrinsic time scale $\rho(s)$, and the volatility $\sigma(s)$ are generally assumed to be constant. The appeal of processes subordinated to a standard Brownian motion $W$ by an intrinsic time process $T$ with non-negative stationary independent increments is also due to the option pricing formula which follows from the classical Black-Scholes one in a frictionless complete market and a risk-minimizing strategy in incomplete markets. (In incomplete markets, there exist nonredundant claims carrying an intrinsic risk. In order to evaluate a contingent claim, a risk-minimizing strategy is often applied (see Hofmann et al. [27], Follmer and Sondermann [28], and Follmer and Schweizer [29]).) Hurst et al.'s stable subordinated model [21] uses the unique continuous martingale that makes sense in a discrete setting, but a priori it is not derived from a risk-minimizing strategy even if the markets are incomplete (see Rachev and Mittnik [20]). Following the same notation as in Merton's framework, the value of a European call option at time $t$ (the value of company's equity) with exercise price $L$ (face value of a zerocoupon debt instrument) and time to maturity $t$ (here, we change the notation of maturity time from $T$ (used in the Merton's framework) to $t$ since $T$ denotes the intrinsic time 
process in the subordinated option pricing models) is given by

$$
E_{t}=A\left(t_{0}\right) F_{+}\left(\ln \left(\frac{A\left(t_{0}\right)}{L_{r, t_{0}, t}}\right)\right)-L_{r, t_{0}, t} F_{-}\left(\ln \left(\frac{A\left(t_{0}\right)}{L_{r, t_{0}, t}}\right)\right),
$$

where

$$
F_{ \pm}(x)=\int_{0}^{+\infty} \Phi\left(\frac{x \pm(1 / 2) y}{\sqrt{y}}\right) d F_{Y}(y)
$$

$\Phi(\cdot)$ is the cumulative distribution function of the standard normal variable, $F_{Y}$ is the cumulative distribution function of a random variable $Y=\int_{t_{0}}^{t} \sigma^{2}(s) d T(s)$, and $L_{r, t_{0}, t}=$ $L \exp \left(-\int_{t_{0}}^{t} r(s) d s\right)$ is the discounted exercise price (the right continuous with left-hand limits (RCLL) time-dependent function $r(t)$ defines the short term interest rate). Considering a continuous distribution of the random variable $Y$ with density function $f_{Y}$, then $F_{ \pm}(x)$ can now be numerically integrated over the finite interval $[0,1]$ the transformation $y=u(1-u)^{-3}$ (see Rachev and Mittnik [20]); that is,

$$
\begin{aligned}
F_{ \pm}(x)= & \int_{0}^{+\infty} \Phi\left(\frac{x \pm(1 / 2) \lambda y}{\sqrt{\lambda y}}\right) f_{Y}(y) d y \\
= & \int_{0}^{1} \Phi\left(\frac{x \pm(1 / 2) \lambda u(1-u)^{-3}}{\sqrt{\lambda u(1-u)^{-3}}}\right) \\
& \times f_{Y}\left(u(1-u)^{-3}\right) \frac{1+2 u}{(1-u)^{4}} d u .
\end{aligned}
$$

Moreover, as for the classical Black-Scholes model, in the case of subordinated models, we can also monitor the variation in the derivative price with respect to the parameters that enter into the option formula (i.e., the Greeks). For our purposes, it is sufficient to define delta, which is given by

$$
\text { delta }=\Delta_{E}=\frac{\partial E_{t}}{\partial A}=F_{+}\left(\ln \left(\frac{A\left(t_{0}\right)}{L_{r, t_{0}, t}}\right)\right) .
$$

Analogously to the Merton model, the probability of default can be estimated under the risk neutral probability measure as follows:

$$
\begin{aligned}
\mathrm{PD}_{t} & =F_{+}\left(\ln \left(\frac{L_{r, t_{0}, t}}{A\left(t_{0}\right)}\right)\right) \\
& =\int_{0}^{+\infty} \Phi\left(\frac{\ln \left(L_{r, t_{0}, t} / A\left(t_{0}\right)\right)+(1 / 2) y}{\sqrt{y}}\right) d F_{Y}(y) .
\end{aligned}
$$

Recall that under the risk neutral measure the stationary increment $Z(t+s)-Z(t)$ has mean $\mu_{Z, s}=0$ and variance $\sigma_{Z, s}^{2}=\mu_{T, s} \sigma^{2}$, where $\sigma$ and $\mu_{T, s}$ are, respectively, the volatility and the mean of the increment of the stationary process $T$ when they exist (see [21]). The skewness coefficient of this increment is zero (models are symmetric around the zero mean). Kurtosis of the subordinated models is defined as $k_{Z, s}=3\left(\left(1+\sigma_{T, s}^{2}\right) / \mu_{T, s}\right)$, for all $s \geq 0$ (where $\sigma_{T, s}^{2}$ is the variance of the random variable $T(t+s)-T(t)$ when it exists); that is, subordinated models with intrinsic random time are leptokurtic. Thereby, the model we consider in the following presents heavier tails and higher peaks around the origin than the normal distribution.

2.3. The Mandelbrot-Taylor Distributional Assumptions. Mandelbrot [14-16] and Mandelbrot and Taylor [22] have proposed the stable Paretian distribution to estimate the log-returns. An $\alpha$-stable distribution $S_{\alpha}=(\sigma, \beta, \mu)$ depends on four parameters: the index of stability $\alpha \in(0,2](\alpha=2$ in the Gaussian case), the skewness parameter $\beta \in[-1,1]$, the scale parameter $\sigma \in(0,+\infty)$, and the location parameter $\mu \in(-\infty,+\infty)$ (see Samorodnitsky and Taqqu [30] for further details on stable distributions). Mandelbrot and Taylor [22] supposed that the intrinsic time process $T$ has stationary independent increments as follows:

$$
T(t+s)-T(t) \stackrel{d}{=} S_{\alpha / 2}\left(c s^{2 / \alpha}, 1,0\right),
$$

for all $s, t \geq 0, \alpha \in(0,2)$, and $c>0$. Here, the index of stability is $\alpha / 2$; the scale parameter is $c s^{\alpha / 2}$; the stable skewness is 1; and the location parameter is zero. Under the Mandelbrot-Taylor assumptions; the subordinated process $Z(t)=\ln \left(A_{t h}\right)$ is a symmetric $\alpha$-stable Lévy motion with stationary independent increments as follows:

$$
Z(t+s)-Z(t)=\ln \left(\frac{A_{t h}}{A_{(t-s) h}}\right) \stackrel{d}{=} S_{\alpha}\left(v s^{1 / \alpha}, 0,0\right),
$$

for all $s, t>0$, where

$$
\nu=\frac{\sigma \sqrt{c}}{\sqrt{2}(\cos (\pi \alpha / 4))^{1 / \alpha}} .
$$

If we consider the constant scalar parameter $\sigma$, then the random variable $Y$ in (11) is as follows:

$$
Y=\sigma^{2}\left(T(t)-T\left(t_{0}\right)\right)=\lambda V
$$

where $\lambda=c \sigma^{2}\left(t-t_{0}\right)^{2 / \alpha}$ and $V=S_{\alpha / 2}(1,1,0)$. Hence, with

$$
c=2\left(\cos \left(\frac{\pi \alpha}{4}\right)\right)^{2 / \alpha}
$$

it follows that $Z(t) \stackrel{d}{=} S_{\alpha}\left(\sigma t^{1 / \alpha}, 0,0\right)$. Thus, we can estimate the index of stability $\alpha$ and the scalar parameter $\sigma$ using the maximum likelihood method (see [20] and the references therein). Moreover, considering the density function $f_{V}$ of the $\alpha / 2$ stable random variable $V$, we obtain the following expression for $F_{ \pm}(x)$ :

$$
\begin{aligned}
F_{ \pm}(x)=\int_{0}^{1} & \Phi\left(\frac{x \pm(1 / 2) \lambda u(1-u)^{-3}}{\sqrt{\lambda u(1-u)^{-3}}}\right) \\
& \times f_{V}\left(u(1-u)^{-3}\right) \frac{1+2 u}{(1-u)^{4}} d u .
\end{aligned}
$$


The probability of default under the risk neutral probability measure is then given by

$$
\begin{aligned}
\mathrm{PD}_{t}=\int_{0}^{1} & \Phi\left(\frac{\ln \left(L_{r, t_{0}, t} / A\left(t_{0}\right)\right)+(1 / 2) \lambda u(1-u)^{-3}}{\sqrt{\lambda u(1-u)^{-3}}}\right) \\
& \times f_{V}\left(u(1-u)^{-3}\right) \frac{1+2 u}{(1-u)^{4}} d u
\end{aligned}
$$

\section{Estimation Methodology}

While for the Merton model there are just three parameters necessary for the estimation of default probabilities-namely, the company's market value $A_{t}$ at time $t$, the asset drift $\mu$, and the asset volatility $\sigma$-in the case of the subordinated models, we have to estimate the company's market value at time $t$ and the parameters of the subordinated process. Clearly, different distributional hypothesis of the subordinated model could require the estimation of several different parameters. For example, in the $\alpha$ stable Lévy process, once the index of stability $\alpha$ is estimated, the scalar parameter $\sigma$ is the unique parameter that should be estimated since the skewness parameter and the location parameter have been fixed equal to zero in the model.

3.1. Parameter Estimates for the KMV-Merton Model. The unknown parameters of KMV-Merton model come from (5). Since the market value of assets is a random variable and cannot be observed directly, it is impossible to directly estimate the drift and the volatility in a movement of logreturns on $A_{t}$. Therefore, these three parameters have to be estimated in a different way. In fact, we use the observed market value of equity $E_{t}$ along with (5) to estimate them indirectly.

Generally, the starting point for the two iterative methodologies proposed in literature (the maximum likelihood estimation method and the Moody's KMV method) is based on the so-called calibration method (see $[3,5,31]$ or [32]), which finds two unknown parameters $\left(A_{t}\right.$ and $\left.\sigma\right)$ by solving the system of two equations as follows:

$$
\begin{gathered}
E_{t}=A_{t} \Phi\left(d_{1}\right)-L e^{-r(T-t)} \Phi\left(d_{2}\right), \\
\sigma_{E}=\frac{A_{t}}{E_{t}} \Phi\left(d_{1}\right) \sigma,
\end{gathered}
$$

where $\sigma_{E}$ is the standard deviation of the equity log returns $\ln \left(E_{t h} / E_{(t-1) h}\right)$. Nevertheless, this method does not estimate asset drift $\mu$; it determines the risk neutral probability of default PD using the risk free asset $r$. As a consequence, Jovan [33] showed that this method provides different estimates of probability of defaults for the same obligors compared to the two following iterative methodologies: the maximum likelihood estimation method and the Moody KMV method.

3.1.1. Maximum Likelihood Estimation Method. This methodology was initially proposed by Duan [13] and enhanced by
Duan et al. [34] later. The time series of daily market value of equity $E_{t}$ is equal to $n$ days, where $t=(0, \ldots, n)$. In Duan et al. [34] the time step $h$ is introduced. Typically, the value of this coefficient for daily data would be $h=1 / 250$. The methodology is iterative. Then, the following log-likelihood function for the estimation of $\mu$ and $\sigma$ of model (3), where th $=(0, \ldots, n h)$, is defined on the basis of observed values of $E_{t}$ as follows:

$$
\begin{aligned}
L\left(\widehat{\theta} ; \widehat{A}_{t h} \mid E_{t h}\right)= & -\frac{n}{2} \ln \left(2 \pi \widehat{\sigma}^{2} h\right) \\
& -\frac{1}{2} \sum_{t=1}^{n} \frac{\left(\widehat{R}_{t}-\left(\widehat{\mu}-(1 / 2) \widehat{\sigma}^{2}\right) h\right)^{2}}{\widehat{\sigma}^{2} h} \\
& -\sum_{t=1}^{n} \ln \left(\widehat{A}_{t h}\right)-\sum_{t=1}^{n} \ln \left(\Phi\left(d_{1}\right)\right),
\end{aligned}
$$

where

$$
\widehat{R}_{t}=\ln \left(\frac{\widehat{A}_{t h}}{\widehat{A}_{(t-1) h}}\right)
$$

and where $\widehat{\theta} \equiv(\widehat{\mu}, \widehat{\sigma})$ and $\widehat{A}_{t h}$ is estimated from (5). To launch the iteration process we could insert as initial values entered into the iteration process the values obtained by solving the system (23). Despite the fact that these estimates are not the best ones from a solution point of view, they can be good enough as the initial values for different kinds of iterative procedures. Each iteration produces a time series of daily values $\widehat{A}_{t h}^{(i)}$, where the debt maturity ranges over $1 \leq$ $(T-t h) \leq T$. We maximize (24) to obtain estimates of the unobserved asset drift and volatility $\widehat{\theta}^{(i)}$. Since this is an iterative procedure, we use the new estimates obtained from (24) and the new market value of assets obtained from (5) for maximizing (24) once again. The procedure is repeated until the differences in $\widehat{\mu}^{(i)}$ and $\widehat{\sigma}^{(i)}$ between the successive iterations are sufficiently small (i.e., until $\left|\widehat{\mu}^{(i+1)}-\widehat{\mu}^{(i)}\right|+$ $\left|\widehat{\sigma}^{(i+1)}-\widehat{\sigma}^{(i)}\right| \leq \varepsilon$ for a given small $\varepsilon$ ).

Duan et al. [34] found that the Moody's KMV method provides the same estimates as the MLE method, even though they state that the latter method is preferable for inference statistics.

3.1.2. Moody's KMV Methodology. This iterative procedure follows a disclosed part of Moody's KMV methodology for a calculation of expected default frequency (see Duan et al. [34], Duffie et al. [9], Crosbie and Bohn [5], or Vassalou and Xing [35]). This method is quite similar to the MLE method. The unique difference is that in order to obtain estimates of the asset drift and volatility, instead of maximizing the loglikelihood function, we have explicit formulas.

The first step is exactly the same calculation of the daily value of $\widehat{A}_{t h}^{(i)}$, th $=(0, \ldots, n h)$ from (5). As the initial values can be used again, the estimates can be obtained by solving 
the system (23). Then, the arithmetic mean of the sample is given by

$$
\bar{R}^{(i)}=\frac{1}{n} \sum_{t=1}^{n} \widehat{R}_{t}^{(i)},
$$

where $\widehat{R}_{t}$ is defined in (25). Another step is the calculation of estimates of the asset volatility $\widehat{\sigma}$ and the drift $\widehat{\mu}$ of model (3) which are defined as follows:

$$
\begin{gathered}
\widehat{\sigma}^{(i+1)}=\sqrt{\frac{1}{n h} \sum_{t=1}^{n}\left(\widehat{R}_{t}^{(i)}-\bar{R}^{(i)}\right)^{2}}, \\
\widehat{\mu}^{(i+1)}=\bar{R}^{(i)} \frac{1}{h}+\frac{1}{2} \widehat{\sigma}^{2(i+1)} .
\end{gathered}
$$

Since this is again an iterative procedure, we use the new estimates obtained from $(27)$ to calculate $A_{t h}^{(i+1)}$. The procedure is repeated until the differences in $\widehat{\mu}$ and $\widehat{\sigma}$ among successive iterations are sufficiently small.

It is worth to mention that the Merton model with parameters estimated according to the methodology described above differs from the one actually employed by Moody's KMV. How well the Merton model performs substantially relies on the simplifying assumptions facilitating its implementation. These simplifying assumptions are not really realistic in practice, though. That is why Moody's KMV does not rely solely on these assumptions. (In 2002, Moody's Corporation completed acquisition of KMV. KMV Corporation is now renamed as Moody's KMV.) Indeed, the founders of KMV, Oldrich Vasicek and Stephen Kealhofer, developed a new model called Vasicek-Kealhofer (VK) (see Arora et al. [36]) to estimate the distance-to-default of an individual company. One of the most important differences is that while we use the cumulative normal distribution to convert distances-to-default into "real" (non risk-neutral) default probabilities in classical Merton model, Moody's KMV uses its large historical database to estimate the real empirical distribution of distances-to-default, and it calculates default probabilities based on that distribution.

3.2. Parameter Estimates for Subordinated Models. We can extend the estimation methodologies proposed for the KMVMerton model in order to estimate the parameters of a subordinated model.

3.2.1. Maximum Likelihood Estimation Method. Obviously, in order to use this method, we have to revise (24). Actually, (24) can be derived from the more general formula which can be used for the derivation of log-likelihood functions for any subordinated model. This formula is defined in the following way:

$$
\begin{aligned}
& L\left(\widehat{\theta} ; \widehat{A}_{t h} \mid E_{t h}\right) \\
& \quad=\sum_{t=1}^{n} \ln \left(f_{Z}\left(\widehat{R}_{t}\right)\right)-\sum_{t=1}^{n} \ln \left(\widehat{A}_{t h}\right)-\sum_{t=1}^{n} \ln \left(\Delta_{E}\right),
\end{aligned}
$$

where $\widehat{\theta}$ represents the set of the parameters in the density function $f_{Z}\left(\widehat{R}_{t}\right)$ of the stationary increment $\ln \left(A_{t h} / A_{(t-1) h}\right)=$ $Z(t+1)-Z(t), \widehat{A}_{t h}$ is estimated from (11), $\widehat{R}_{t}$ is defined in (25), and $\Delta_{E}$ is given by (14). The initial values $\widehat{A}_{t h}^{(1)}$ of the iteration process could be the ones obtained by solving the system (23). The procedure continues iteratively till the distance $\left\|\widehat{\theta}^{(i+1)}-\widehat{\theta}^{(i)}\right\|$ is sufficiently small. Typically, there are two problems regarding this maximum likelihood method. The first difficulty is related to computation time. This method generally presents more local optima, and it can be very time consuming to reach a global optimum. Secondly, it is often very problematic to implement this methodology since many subordinated models do not have close form equation for the density function $f_{Z}$.

3.2.2. An Extended KMV Methodology. As for Moody's KMV iterative methodology, we have first to compute the daily value of $\widehat{A}_{t h}^{(i)}$, th $=(0, \ldots, n h)$ solving (11), then the other parameters of the subordinated process $\widehat{\theta}^{(i+1)}$ are estimated on the series $\widehat{R}_{t}^{(i)}=\ln \left(\widehat{A}_{t h}^{(i)} / \widehat{A}_{(t-1) h}^{(i)}\right)$ considering the distributional assumption of the subordinated model. The procedure continues iteratively till the distance $\left\|\widehat{\theta}^{(i+1)}-\widehat{\theta}^{(i)}\right\|$ is sufficiently small. In particular, for the $\alpha$ stable Lévy model, we first suggest to determine the index of stability $\alpha$. Secondly, the unique parameter that must be estimated is the scalar parameter $\sigma$ since the skewness parameter and the location parameter are fixed equal to zero. Clearly, even in this case, we need to insert some initial values $\widehat{A}_{t h}^{(1)}$ of the iteration process that could be the ones obtained by solving the system (23). Moreover (as for the Merton model-see Duan et al. [34]), the extended KMV methodology provides the same estimates as the MLE method when the parameter estimates $\widehat{\theta}^{(i+1)}$ are the MLE on the series $\widehat{R}_{t}^{(i)}$.

\section{Application and Results}

In this section, we first describe the data used in the computational analysis and apply the Merton model. Secondly, we test the distributional assumption of this model. Finally, we apply the Stable Lévy model and compare it with the Merton one. In the application of the models, we use the extended KMV methodology.

To apply the previous models to a particular company, we need the market value of equity $E_{t}$, the face value of the zerocoupon debt instrument $L$, and the risk-free interest rate $r$. For risk-free interest rate we used 13-week Treasury bill and Thomson Reuters Datastream dataset to obtain the market value of equity and the face value of the zero-coupon debt instrument of 24 US companies with strong capitalization in US market. (The companies are (1) Boeing, (2) Cisco Systems, (3) Chevron, (4) E. I. du Pont de Nemours, (5) Walt Disney, (6) Home Depot, (7) Hewlett-Packard, (8) IBM, (9) Intel, (10) Johnson \& Johnson, (11) Coca Cola, (12) McDonalds, (13) 3M, (14) Merck \& Co., (15) Microsoft, (16) Pfizer, (17) Procter \& Gamble, (18) AT \& T, (19) UnitedHealth Group, (20) United Technologies, (21) Verizon Communications, (22) WalMart 
Stores, (23) Exxon Mobil, and (24) Travelers Companies.) For a sample period we used data from January 3, 2000, to December 30, 2011. As market value of equity, we used consolidated market value of a company which is defined as a share price multiplied by the number of ordinary shares in issue. Finally, for the face value of the zero-coupon debt instrument, we used the sum of the short-term debt, current portion of the long-term debt, and half of the long-term debt. (There need to be chosen an amount of the debt that is relevant to a potential default during a one year period. Total debt is inadequate when not all of it is due in one year (it is assumed one-year time horizon for debt maturity and subsequent estimation of PD), as the firm may remain solvent even when the value of assets falls below its total liabilities. Using the short-term debt for the default barrier would be often wrong, for instance, when there are covenants that force the company to serve other debts when its financial situation deteriorates. Prior studies generally follow KMV methodology and choose the short-term debt plus half of the long-term debt for the default barrier (see Bharath and Shumway [37], Vassalou and Xing [35] or Duffie et al. [9]).) While the short-term debt and current portion of the longterm debt represent that portion of the debt payable within one year including current portion of the long-term debt and sinking fund requirements of preferred stock or debentures, the long-term debt represents all interest bearing financial obligations excluding amounts due within one year.

4.1. Analysis of the Distributional Assumption of the Company Value Log-Returns. The Merton model distributional assumption implies that the unobservable company value log-returns are Gaussian distributed. In order to test this assumption, we use the daily log-returns of the companies' assets value obtained from both the KMV-Merton model and the alpha stable Lévy model, from January 3, 2000, to December 30, 2011 (for a total of 3157 daily values).

First of all, we test the Gaussian and the stable nonGaussian hypotheses on the company value log-returns obtained from the KMV-Merton model. Thus, we compute different statistics every day on the last 250 daily company values (1 year of daily values). Table 1 reports the average among all the firms and for all the expost period of different statistics applied to company value logreturns to test the Gaussian hypothesis and the stable non-Gaussian hypothesis. In particular we consider the average of the follwing: the mean, the standard deviation, the skewness $E\left((X-E(X))^{3}\right) / E\left((X-E(X))^{2}\right)^{1.5}$, the kurtosis $E\left((X-E(X))^{4}\right) / E\left((X-E(X))^{2}\right)^{2}$, the percentage of rejection of the Gaussian hypothesis using the Jarque-Bera (JB) test (at the 5\% significance level) (see [38]), the stable index of stability "alpha," the stable index of skewness "beta," the stable scalar parameter "sigma," the stable location parameter "mu," and the percentage of rejection of the stable Paretian hypothesis using the Kolmogorov-Smirnov (K-S) test (at the $5 \%$ significance level).

In particular, the results reported in Table 1 suggest that (1) the returns exhibit heavy tails since the average of the stability parameters alpha is always less than 2 and the average
TABLE 1: Average of some statistics for the daily log-returns of the companies' assets value obtained from the KMV-Merton model.

\begin{tabular}{lc}
\hline Mean & 0.00002 \\
St.dev. & 0.0196 \\
Skewness & -0.6140 \\
Kurtosis & 33.4351 \\
JB test (95\%) & $96.77 \%$ \\
Alpha & 1.7089 \\
Beta & 0.0062 \\
Sigma & 0.0106 \\
Mu & 0.0001 \\
K-S test (95\%) & $16.56 \%$ \\
\hline
\end{tabular}

of kurtosis is much higher than 3; (2) the returns are slightly asymmetric since the average of the skewness parameter and the average of the stable parameter beta are always different from zero; and (3) the Gaussian hypothesis is almost always rejected for all companies while the stable Paretian hypothesis is generally rejected for four companies of the considered sample.

Secondly, we test the different distributional hypothesis of the companies value log-returns obtained by the stable Lévy model using a Kolmogorov-Smirnov (K-S) test (at the $5 \%$ significance level). From this test, we observe almost the same percentage of rejection $(16.55 \%)$ we get using the companies value log-returns as that obtained from the KMVMerton model (16.56\%). Similarly, we get $98.44 \%$ of rejection of the Gaussian hypothesis applying the Jarque-Bera test to the companies value log-returns obtained by stable Lévy model (compared to $96.77 \%$ obtained from the KMV-Merton model).

From this preliminary analysis, we deduce that the classical distributional hypothesis of the Merton model is almost never verified. Moreover, the stable non-Gaussian hypothesis appears more realistic than the Gaussian one. Therefore, it is appropriate to apply a Stable Lévy model which is able to capture empirically observed anomalies that contradict the classical normality assumption. The results we get here are not a real surprise since the stable Paretian laws generalize the Gaussian one.

4.2. Estimate of Default Probabilities with KMV-Merton Model. We used Moody's KMV methodology (We perform our analysis using MATLAB.) for the estimation of the parameters for the Merton model used for the computation of the probability of default of any company. The results of the empirical analysis are reported in Figure 1 and Table 2. In Table 2, there are listed average values of ratio between the debt and the company's assets value and average values of risk neutral PD and distance-to-default obtained from the KMVMerton model for any company. In particular, we observe that generally when the average ratio between debt and company value is high, we observe an analogous higher probability of default and a lower distance to default. This aspect could be a problem when the KMV-Merton model is used to compute the risk neutral and real probabilities of default of a bank since 


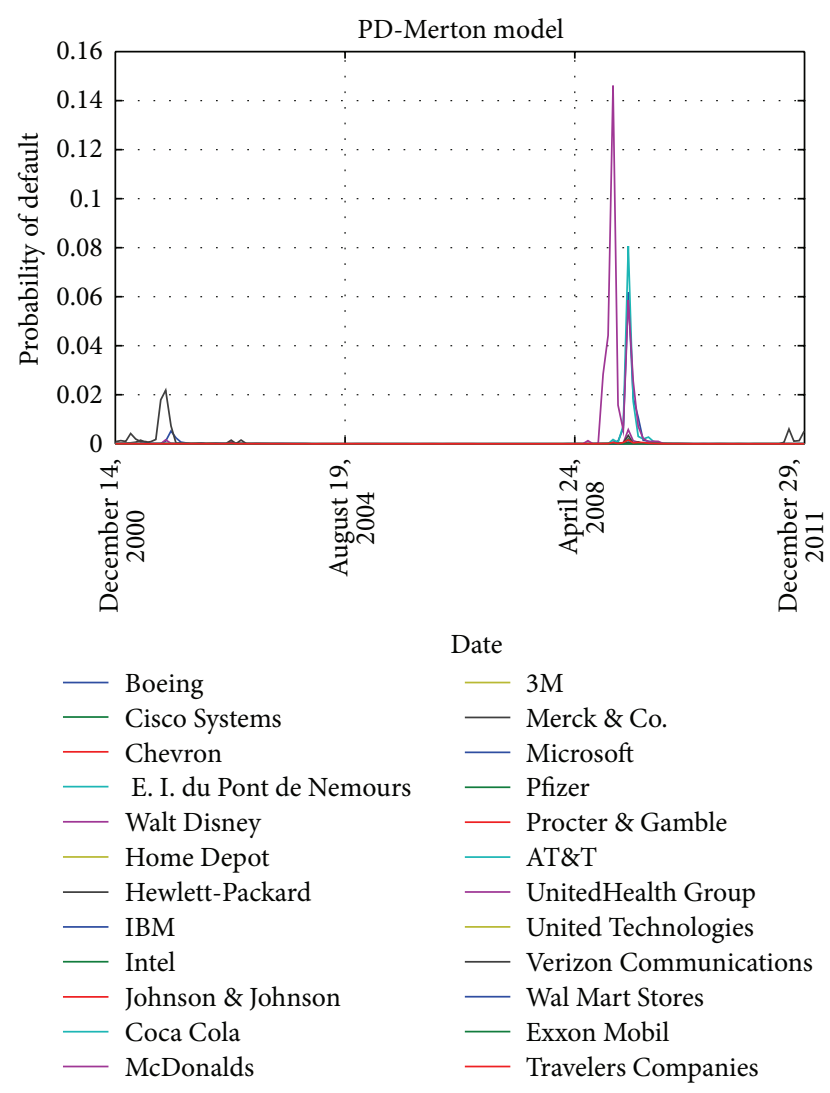

Figure 1: PDs-KMV-Merton model.

financial institutions have significantly greater debt compared to other companies. Therefore, the Merton model is not plausible for the estimation of PDs of financial institutions unless some adjustments are made. (For example, Byström [39] shows that one of the main implications of his simplified "spread sheet" version of the Merton model is the fact that the default probability's insensitivity to the leverage ratio at high levels of debt makes it possible to apply his model to banks and other highly leveraged firms.)

Moreover, Figure 1 describes the evolution of the risk neutral PDs on the monthly basis. These probabilities are almost null during all the decade. However, we can distinguish three periods of increased PDs for some companies which are as follows: at the beginning of the century after the high tech crisis and September 11, during the subprime crisis, and during the country credit risk crisis. During the first period and the country credit risk crisis, the most evident grown of PD is due to the Hewlett-Packard firm (its PD increased up to $2.1 \%$ in the first period and to $1 \%$ in the last one). The period with more significant growth in PDs is dated from September 2008. This might be easily explained by the subprime mortgage crisis that reached a critical stage during the first week of September 2008 and was characterized by severely contracted liquidity in the global credit markets and insolvency threats to investment banks and other institutions. Beginning with bankruptcy of Lehman Brothers on September 14, 2008, the financial crisis entered an acute phase marked by the failures of prominent
TABLE 2: Average values of ratio $(L / A)$ and risk neutral PD and DD obtained from the KMV-Merton model.

\begin{tabular}{|c|c|c|c|}
\hline Company & $\begin{array}{c}\text { Average ratio } \\
(L / A)\end{array}$ & $\begin{array}{l}\text { Average } \\
\text { PD }\end{array}$ & $\begin{array}{l}\text { Average } \\
\text { DD }\end{array}$ \\
\hline (1) Boeing & 0.1326 & 0.000830 & 8.9020 \\
\hline (2) Cisco Systems & 0.0262 & 0.000000 & 20.6010 \\
\hline (3) Chevron & 0.0613 & 0.000000 & 13.8524 \\
\hline $\begin{array}{l}\text { (4) E. I. du Pont de } \\
\text { Nemours }\end{array}$ & 0.1169 & 0.000845 & 9.9706 \\
\hline (5) Walt Disney & 0.1312 & 0.000083 & 8.5109 \\
\hline (6) Home Depot & 0.0600 & 0.000002 & 11.8297 \\
\hline (7) Hewlett-Packard & 0.0909 & 0.000511 & 8.3242 \\
\hline (8) IBM & 0.1037 & 0.000000 & 11.4799 \\
\hline (9) Intel & 0.0099 & 0.000000 & 14.2761 \\
\hline $\begin{array}{l}\text { (10) Johnson \& } \\
\text { Johnson }\end{array}$ & 0.0331 & 0.000000 & 22.8225 \\
\hline (11) Coca Cola & 0.0615 & 0.000000 & 17.5142 \\
\hline (12) McDonalds & 0.1031 & 0.000015 & 12.2037 \\
\hline (13) $3 \mathrm{M}$ & 0.0493 & 0.000000 & 14.9342 \\
\hline (14) Merck \& Co. & 0.0611 & 0.000037 & 11.1672 \\
\hline (15) Microsoft & 0.0068 & 0.000000 & 21.4008 \\
\hline (16) Pfizer & 0.0815 & 0.000019 & 11.0915 \\
\hline $\begin{array}{l}\text { (17) Procter \& } \\
\text { Gamble }\end{array}$ & 0.1010 & 0.000000 & 13.9819 \\
\hline (18) AT\&T & 0.1619 & 0.000013 & 8.4346 \\
\hline $\begin{array}{l}\text { (19) UnitedHealth } \\
\text { Group }\end{array}$ & 0.0924 & 0.002424 & 10.2912 \\
\hline $\begin{array}{l}\text { (20) United } \\
\text { Technologies }\end{array}$ & 0.0800 & 0.000001 & 12.1045 \\
\hline $\begin{array}{l}\text { (21) Verizon } \\
\text { Communications }\end{array}$ & 0.2117 & 0.000106 & 8.8750 \\
\hline (22) Wal Mart Stores & 0.0957 & 0.000000 & 12.4895 \\
\hline (23) Exxon Mobil & 0.0208 & 0.000000 & 18.0516 \\
\hline $\begin{array}{l}\text { (24) Travelers } \\
\text { Companies }\end{array}$ & 0.1298 & 0.000035 & 8.9095 \\
\hline
\end{tabular}

American and European banks and efforts by the American and European governments to rescue distressed financial institutions. Among the companies from our sample which were affected the most by this crisis belong UnitedHealth Group, E. I. du Pont de Nemours, and Boeing. UnitedHealth Group is a care company which offers a spectrum of products and services. This company suffered a jump in PD from $0 \%$ in May 2008 up to $14.6 \%$ in November 2008. E. I. du Pont de Nemours is a chemical company and was the world's third largest chemical company based on market capitalization in 2009. This company's PD increased from $0 \%$ in October 2008 to $8.1 \%$ in February 2009. Finally, Boeing as a representative of aerospace industry suffered an increase in PD from $0 \%$ in October 2008 to $6.2 \%$ in February 2009. This phase of financial crisis lasted approximately one year, and in October 2009 the values of PD of observed companies went back to zero. 
TABLE 3: Indexes of stability alpha average values of ratio $(L / A)$, and risk neutral PD and DD obtained from the stable Lévy model.

\begin{tabular}{|c|c|c|c|c|}
\hline Company & Alpha & $\begin{array}{c}\text { Average } \\
\text { ratio } \\
(L / A)\end{array}$ & $\begin{array}{l}\text { Average } \\
\text { PD }\end{array}$ & $\begin{array}{c}\text { Average } \\
\text { DD }\end{array}$ \\
\hline (1) Boeing & 1.6619 & 0.1308 & 0.0149 & 8.9153 \\
\hline (2) Cisco Systems & 1.5756 & 0.0262 & 0.0116 & 20.4104 \\
\hline (3) Chevron & 1.6671 & 0.0606 & 0.0067 & 13.7868 \\
\hline $\begin{array}{l}\text { (4) E. I. du Pont de } \\
\text { Nemours }\end{array}$ & 1.6575 & 0.1169 & 0.0137 & 10.0480 \\
\hline (5) Walt Disney & 1.5680 & 0.1305 & 0.0265 & 8.5155 \\
\hline (6) Home Depot & 1.6101 & 0.0599 & 0.0173 & 11.9741 \\
\hline (7) Hewlett-Packard & 1.5850 & 0.0914 & 0.0253 & 8.3069 \\
\hline (8) IBM & 1.6110 & 0.1032 & 0.0120 & 11.5404 \\
\hline (9) Intel & 1.6411 & 0.0098 & 0.0131 & 14.3321 \\
\hline $\begin{array}{l}\text { (10) Johnson \& } \\
\text { Johnson }\end{array}$ & 1.5803 & 0.0330 & 0.0068 & 22.9854 \\
\hline (11) Coca Cola & 1.5505 & 0.0614 & 0.0120 & 17.6094 \\
\hline (12) McDonalds & 1.7570 & 0.1012 & 0.0032 & 12.3247 \\
\hline (13) $3 \mathrm{M}$ & 1.5590 & 0.0494 & 0.0136 & 14.9028 \\
\hline (14) Merck \& Co. & 1.5909 & 0.0610 & 0.0150 & 11.1738 \\
\hline (15) Microsoft & 1.5459 & 0.0068 & 0.0082 & 21.1204 \\
\hline (16) Pfizer & 1.6691 & 0.0813 & 0.0085 & 11.2040 \\
\hline $\begin{array}{l}\text { (17) Procter \& } \\
\text { Gamble }\end{array}$ & 1.4745 & 0.1010 & 0.0204 & 13.9846 \\
\hline (18) AT\&T & 1.5985 & 0.1607 & 0.0176 & 8.5163 \\
\hline $\begin{array}{l}\text { (19) UnitedHealth } \\
\text { Group }\end{array}$ & 1.5839 & 0.0925 & 0.0256 & 10.3436 \\
\hline $\begin{array}{l}\text { (20) United } \\
\text { Technologies }\end{array}$ & 1.6064 & 0.0798 & 0.0138 & 12.0951 \\
\hline $\begin{array}{l}\text { (21) Verizon } \\
\text { Communications }\end{array}$ & 1.6645 & 0.2106 & 0.0114 & 8.9470 \\
\hline (22) Wal Mart Stores & 1.6398 & 0.0955 & 0.0080 & 12.5641 \\
\hline (23) Exxon Mobil & 1.6494 & 0.0207 & 0.0060 & 18.1822 \\
\hline $\begin{array}{l}\text { (24) Travelers } \\
\text { Companies }\end{array}$ & 1.4659 & 0.1291 & 0.0464 & 8.9419 \\
\hline
\end{tabular}

4.3. Estimate of Default Probabilities with the Stable Lévy Model. In order to evaluate the stable Lévy model, we estimate the parameters using the extended KMV methodology. First of all, we compute the indices of stability on the daily log-returns of the companies' asset values, obtained by the stable Lévy model, which are reported in Table 3 . To evaluate the stable parameters and the distributions of subordinator $f_{V}$ in (21), we perform a maximum likelihood estimator that uses the fast Fourier transform (see $[1,20,40])$. The estimated index of stability is maintained constant for each firm and for all the period of analysis. Clearly, we could adapt more dynamically the model requiring that the index of stability changes periodically with the scalar and location stable parameters. However, this should require the knowledge of the subordinator density distribution $f_{V}$ that changes with the index of stability. Since this distribution is obtained by inverting the Fourier transform, the iterating procedure of the
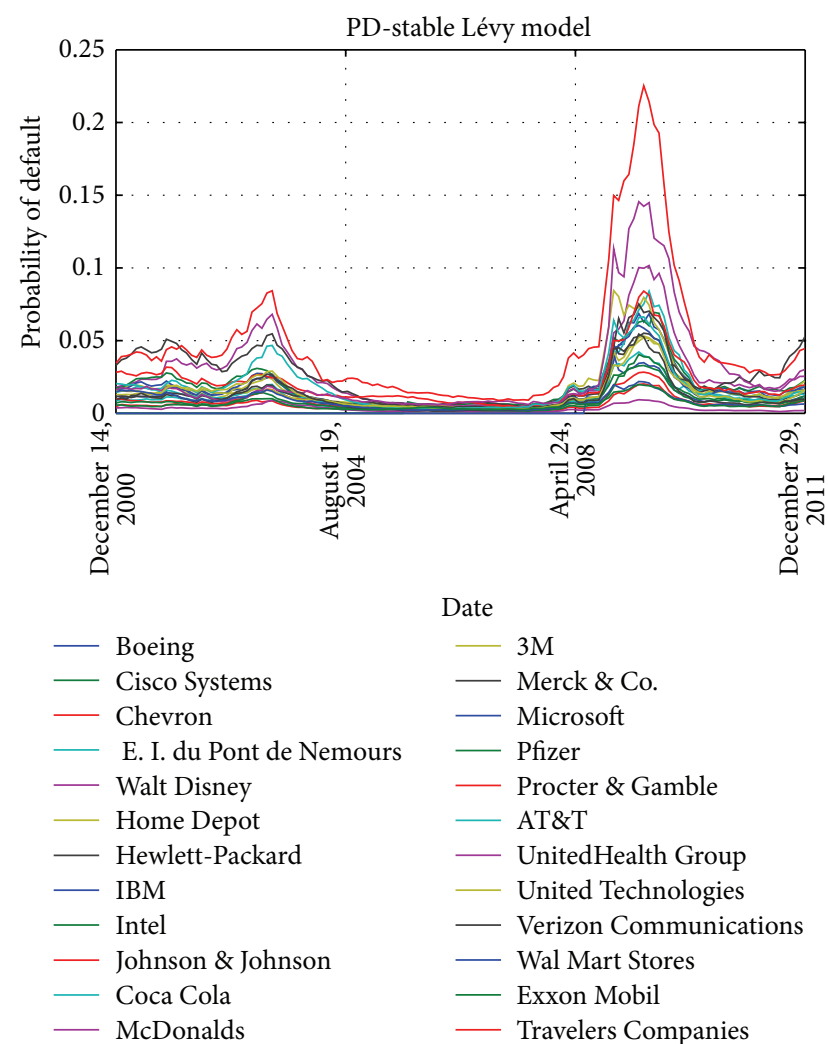

Date

$-3 \mathrm{M}$

- Merck \& Co

- Microsoft

Pfizer

- Procter \& Gamble

- AT\&T

— UnitedHealth Group

_ United Technologies

_ Verizon Communications

_ Wal Mart Stores

_ Exxon Mobil

_ Travelers Companies

Figure 2: PDs-stable Lévy model.

KMV methodology would require too long computational time in that case. In Table 3, there are also listed the average values of ratio between the debt and the company's assets value and average values of risk neutral PD and distance-todefault obtained from the stable Lévy model for any company.

4.4. Comparison of the Two Models. In particular, we observe that there are not very large differences between the company values obtained by the stable Lévy model and the company values obtained by the Merton model. This aspect is important since we couldn't expect strong differences in the company values that represent an unobservable objective variable whose big differences could not be easily justifiable. This observation implies that there are not large differences between the two models with respect to the follwing: (1) the average ratio between debt and company value; (2) the average distance-to-default.

Figure 3 reports the main differences between the two models for those companies which present the highest peaks in default probabilities (E. I. du Pont de Nemours, Walt Disney, Hewlett-Packard, UnitedHealth Group, and Travelers Companies). In particular, Figures 3(a) and 3(b) show that the main differences in the ratio between the debt and the company value and between the distances-to-default are concentrated during the high volatility period after September 11, 2001. However, this difference (as remarked previously) is almost null during the big crisis following the Lehman Brothers bankruptcy. Figures 3(c) and 3(d) show default 


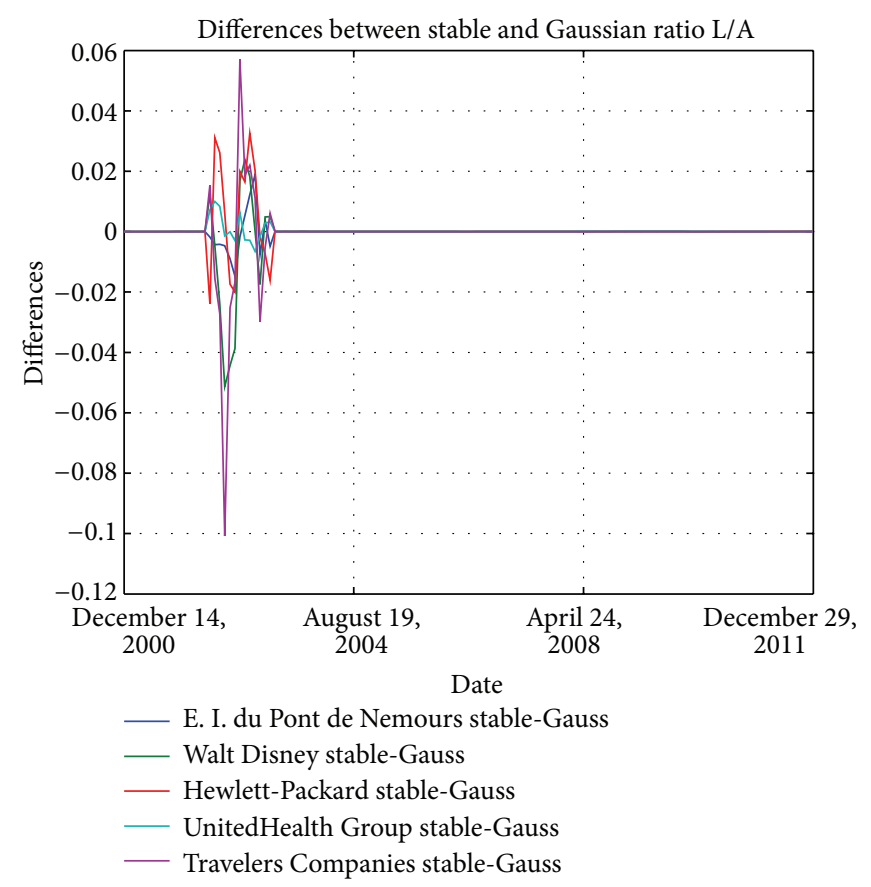

(a)

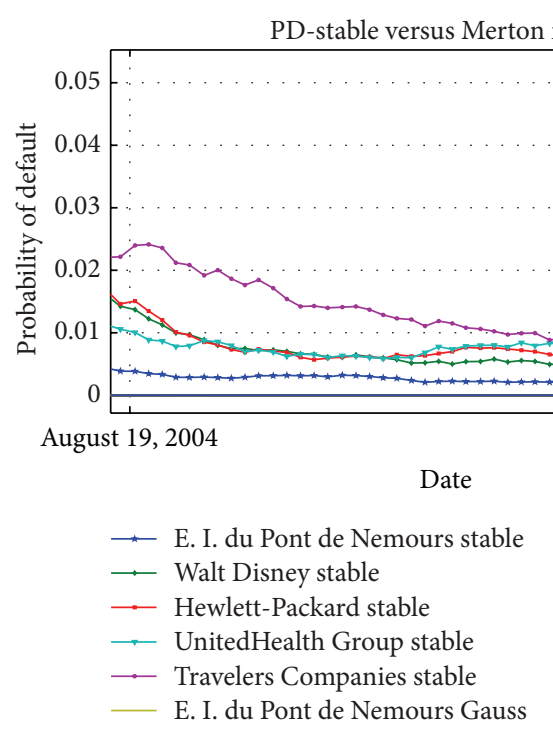

(c)

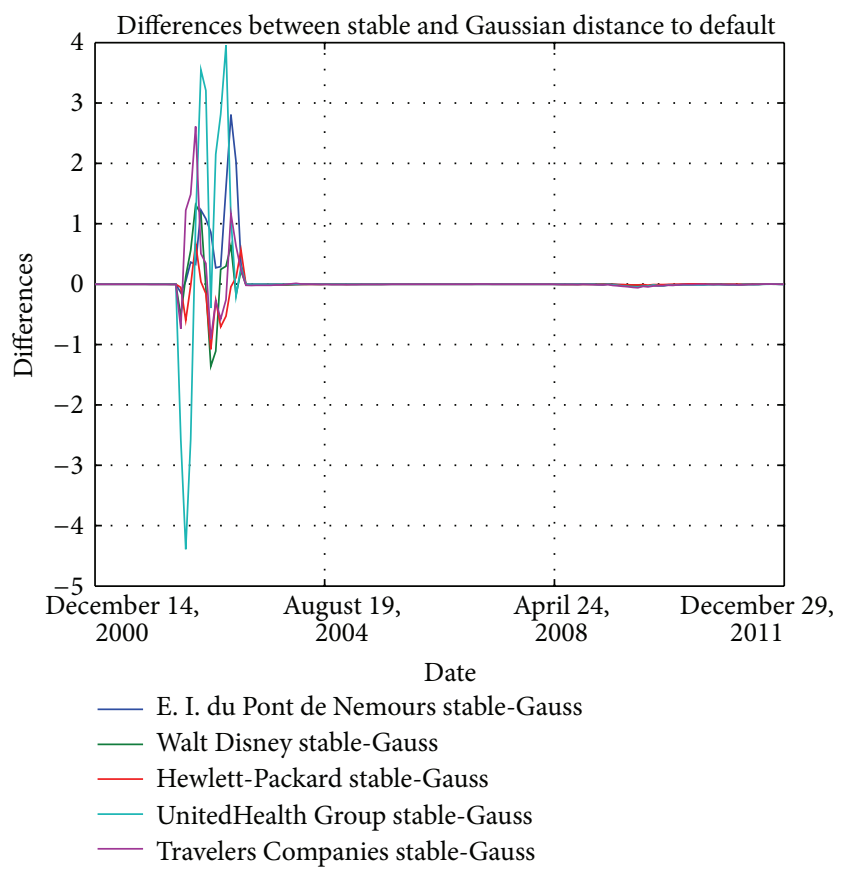

(b)

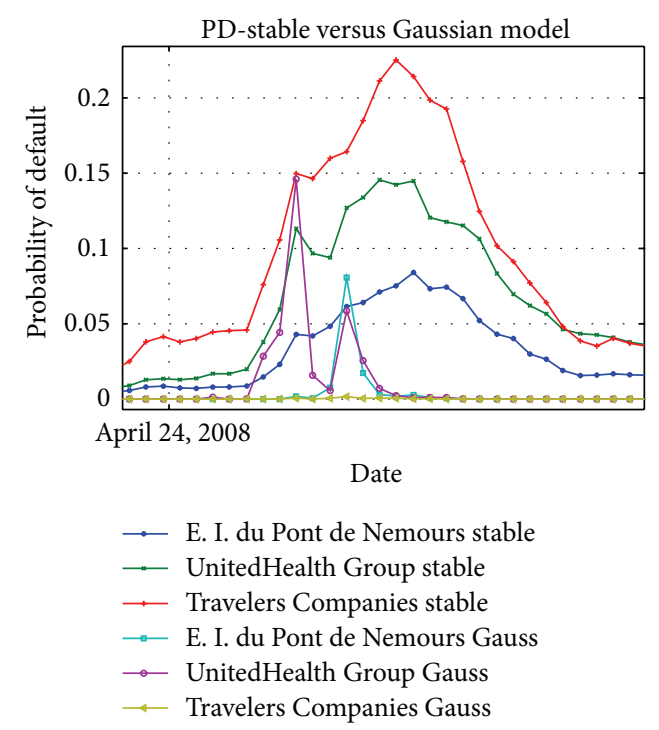

(d)

Figure 3: Differences between Stable Lévy model and KMV-Merton model. (a) Difference between stable ratio $L / A$ and Gaussian ratio. (b) Difference between the stable and Gaussian distance-to-default. (c) Probabilities of default during "calm periods." (d) Probabilities of default during the crisis.

probabilities of chosen companies during "calm" periods and during periods of the crisis. In this case, we observe very big differences among PDs. On one hand, the probabilities of default computed by the Merton model are almost null during the "calm" periods and increase during one or two months of the crisis. On the other hand, the probabilities of default computed by the Lévy stable model are never null during the "calm" periods and become very high during the months of the crisis and in the close subsequent periods.
In particular, we observe the biggest difference for the Travelers Companies for which the Merton model does not register any significant difference in the default probabilities while the stable Lévy model shows the highest values. The reason of this difference is essentially caused by the combination of two aspects. First, the index of stability of the Travelers Companies is very small, and that means very fat tails with high probability of losses. Secondly, the ratio between the debt and the Travelers Companies value is high. This analysis 
confirms the previous one that shows the average default probabilities obtained by the stable Lévy model are much higher than those obtained by the Merton model. This is not a real surprise because while the probability tails of the Gaussian distribution tend to zero exponentially, the probability tails of stable non-Gaussian distribution tend to zero in polynomial order. Thus the probability of losses computed by the stable Lévy model is much higher than the one computed by the Merton model. This effect is also emphasized in Figure 2 that reports the evolution of default probabilities during the decade 2001-2011. Figure 2 shows a much higher sensitivity of these probabilities of all companies with respect to the periods of crises. Moreover, since all the tests have shown that the stable non-Gaussian hypothesis appears more realistic than the Gaussian one, we deduce that the KMVMerton model underestimates the probability of default.

\section{Conclusion}

In this paper, we propose alternative structural credit risk models, and we discuss how to evaluate the probability of default of a given firm under different distributional hypotheses. Finally, we apply and compare the stable Lévy credit risk model with the Merton one. The empirical analysis suggests that the probability of default is generally underestimated by the Merton model. Clearly, these first results should be further discussed and compared with other distributional models in a future research.

\section{Conflict of Interests}

According to the editorial policy of the journal the authors declare that they have no conflict of interests with the firms recalled in the paper.

\section{Acknowledgments}

The authors thank the two anonymous referees for their comments and helpful suggestions that improved the paper greatly. The research was supported by the European Regional Development Fund in the IT4Innovations Centre of Excellence Project (CZ.1.05/1.1.00/02.0070), including the access to the supercomputing capacity, the European Social Fund in the framework of CZ.1.07/2.3.00/20.0296, and the state budget of the Czech Republic. The paper has been also supported by the Italian funds ex MURST 60\% 2011 and MIUR PRIN MISURA Project, 2013-2015.

\section{References}

[1] R. C. Merton, "On the pricing of corporate debt: the risk structure of interest rates," Journal of Finance, vol. 29, pp. 449470, 1974.

[2] F. Black and M. Scholes, "The pricing of options and corporate liabilities," Journal of Political Economy, vol. 81, pp. 637-659, 1973.

[3] C. Bluhm, L. Overbeck, and C. Wagner, An Introduction to Credit Risk Modeling, CRC Press, Boca Raton, Fla, USA, 1st edition, 2003.
[4] D. Duffie and K. J. Singleton, Credit Risk: Pricing, Measurement, and Management, Princeton University Press, Princeton, NJ, USA, 1st edition, 2003.

[5] P. J. Crosbie and J. R. Bohn, "Modelling default risk," Working Paper, KMV Corporation, 2003.

[6] J. R. Bohn, N. Arora, and I. Korablev, "Power and level validation of the EDF credit measure in the U.S. market," Moody's KMV Working Paper, 2005.

[7] Y. Du and W. Suo, "Assessing credit quality from equity markets: is structural model a better approach," Working Paper, Queen's University, 2003.

[8] S. A. Hillegeist, E. K. Keating, D. P. Cram, and K. G. Lundstedt, "Assessing the probability of Bankruptcy," Working Paper, Kellog School of Management, 2002.

[9] D. Duffie, L. Saita, and K. Wang, "Multi-period corporate default prediction with stochastic covariates," Journal of Financial Economics, vol. 83, no. 3, pp. 635-665, 2007.

[10] E. S. Farmen, S. Westgaard, S. Fleten, and N. Wijst, "Default risk and its Greeks under an objective probability measure," in Proceedings of the Stockholm School of Economics-Department of Finance Seminar Series, November 2003.

[11] F. Black and C. Cox, "Valuing corporate securities: some effects of bond indenture provisions," Journal of Finance, vol. 31, no. 2, pp. 351-367, 1976.

[12] J. R. Bohn, "A survey of contingent-claims approaches to risky debt valuation," The Journal of Risk Finance, vol. 1, no. 3, pp. 5370, 2000.

[13] J. C. Duan, "Maximum likelihood estimation using price data of the derivative contract," Mathematical Finance, vol. 4, no. 2, pp. 155-157, 1994.

[14] B. Mandelbrot, "New methods in statistical economics," Journal of Political Economy, vol. 71, pp. 421-440, 1963.

[15] B. Mandelbrot, "The variation of certain speculative prices," Journal of Business, vol. 26, pp. 394-419, 1963.

[16] B. Mandelbrot, "The variation of some other speculative prices," Journal of Business, vol. 40, pp. 393-413, 1967.

[17] E. Fama, "Mandelbrot and the stable Paretian hypothesis," Journal of Business, vol. 36, pp. 420-429, 1963.

[18] E. Fama, "The behavior of stock market prices," Journal of Business, vol. 38, pp. 34-105, 1965.

[19] E. Fama, "Portfolio analysis in a stable Paretian market," Management Science, vol. 11, pp. 404-419, 1965.

[20] S. Rachev and S. Mittnik, Stable Paretian Model in Finance, John Wiley \& Sons, Chichester, UK, 2000.

[21] S. R. Hurst, E. Platen, and S. T. Rachev, "Option pricing for a logstable asset price model," Mathematical and Computer Modelling, vol. 29, no. 10-12, pp. 105-119, 1999.

[22] T. Mandelbrot and M. Taylor, "On the distribution of stock price differences," Operations Research, vol. 15, pp. 1057-1062, 1967.

[23] S. T. Rachev, Handbook of Heavy Tailed Distributions in Finance, Elsevier, Amsterdam, The Netherlands, 2003.

[24] G. Deliandes and R. Geske, "Credit risk and risk neutral default probabilities-information about rating migrations and defaults," Working Paper, UCLA, 2003.

[25] M. F. Osborne, "Brownian motion in the stock market," Operations Research, vol. 7, pp. 145-173, 1959.

[26] W. Feller, An Introduction to Probability Theory and Its Applications II, John Wiley \& Sons, New York, NY, USA, 1966.

[27] N. Hofmann, E. Platen, and M. Schweizer, "Option pricing under incompleteness and stochastic volatility," Tech. Rep., Department of Mathematics, University of Bonn, 1982. 
[28] H. Follmer and D. Sondermann, "Hedging of non-redundant contingent claims," in Contributions to Mathematical Economics, W. Hildenbrand and A. M. Aollell, Eds., pp. 205-223, North-Holland, Amsterdam, The Netherlands, 1986.

[29] H. Follmer and M. Schweizer, "Microeconomic approach to diffusion models for stock prices," Mathematical Finance, vol. 3, pp. 1-23, 1989.

[30] G. Samorodnitsky and M. S. Taqqu, Stable Non-Gaussian Random Processes: Stochastic Models with Infinite Variance, Chapman \& Hall, New York, NY, USA, 1994.

[31] M. Bruche, "Estimating structural bond pricing models via simulated maximum likelihood," 2005, http://www.defaultrisk .com/pp_model_96.htm.

[32] J. Ericsson and J. Reneby, "Estimating structural bond pricing models," Journal of Business, vol. 78, no. 2, pp. 707-736, 2005.

[33] M. Jovan, "The Merton structural model and IRB compliance," Metodološki Zvezki, vol. 7, no. 1, pp. 39-57, 2010.

[34] J. C. Duan, G. Gauthier, and J. G. Simonato, "On the equivalence of the KMV and maximum likelihood methods for structural credit risk models," 2004, http://www.defaultrisk .com/pp_model_97.htm.

[35] M. Vassalou and Y. Xing, "Default risk in equity returns," Journal of Finance, vol. 59, no. 2, pp. 831-868, 2004.

[36] N. Arora, J. R. Bohn, and F. Zhu, "Reduced form versus structural models of credit risk: a case study of three models," Moody's KMV Working Paper, 2005.

[37] S. T. Bharath and T. Shumway, "Forecasting default with the Merton distance to default model," Review of Financial Studies, vol. 21, no. 3, pp. 1339-1369, 2008.

[38] C. M. Jarque and A. K. Bera, "A test for normality of observations and regression residuals," International Statistical Review, vol. 55, no. 2, pp. 163-172, 1987.

[39] H. N. Byström, "Merton for dummies: a flexible way of modelling default risk," Research Paper 112, University of Technology, Sydney, Australia, 2003.

[40] J. P. Nolan, "Numerical calculation of stable densities and distribution functions," Communications in Statistics C, vol. 13, no. 4, pp. 759-774, 1997. 


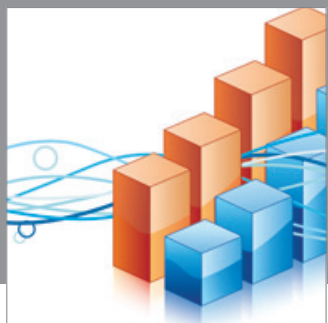

Advances in

Operations Research

mansans

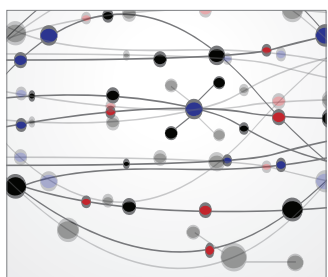

The Scientific World Journal
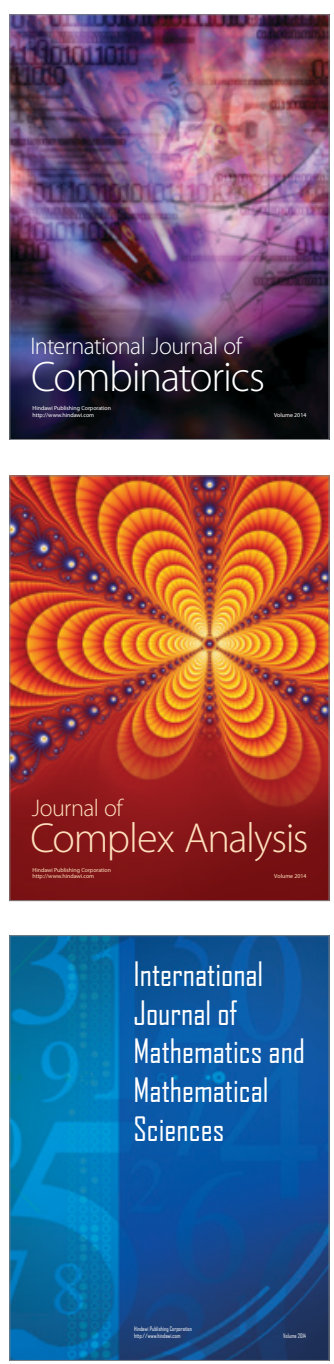
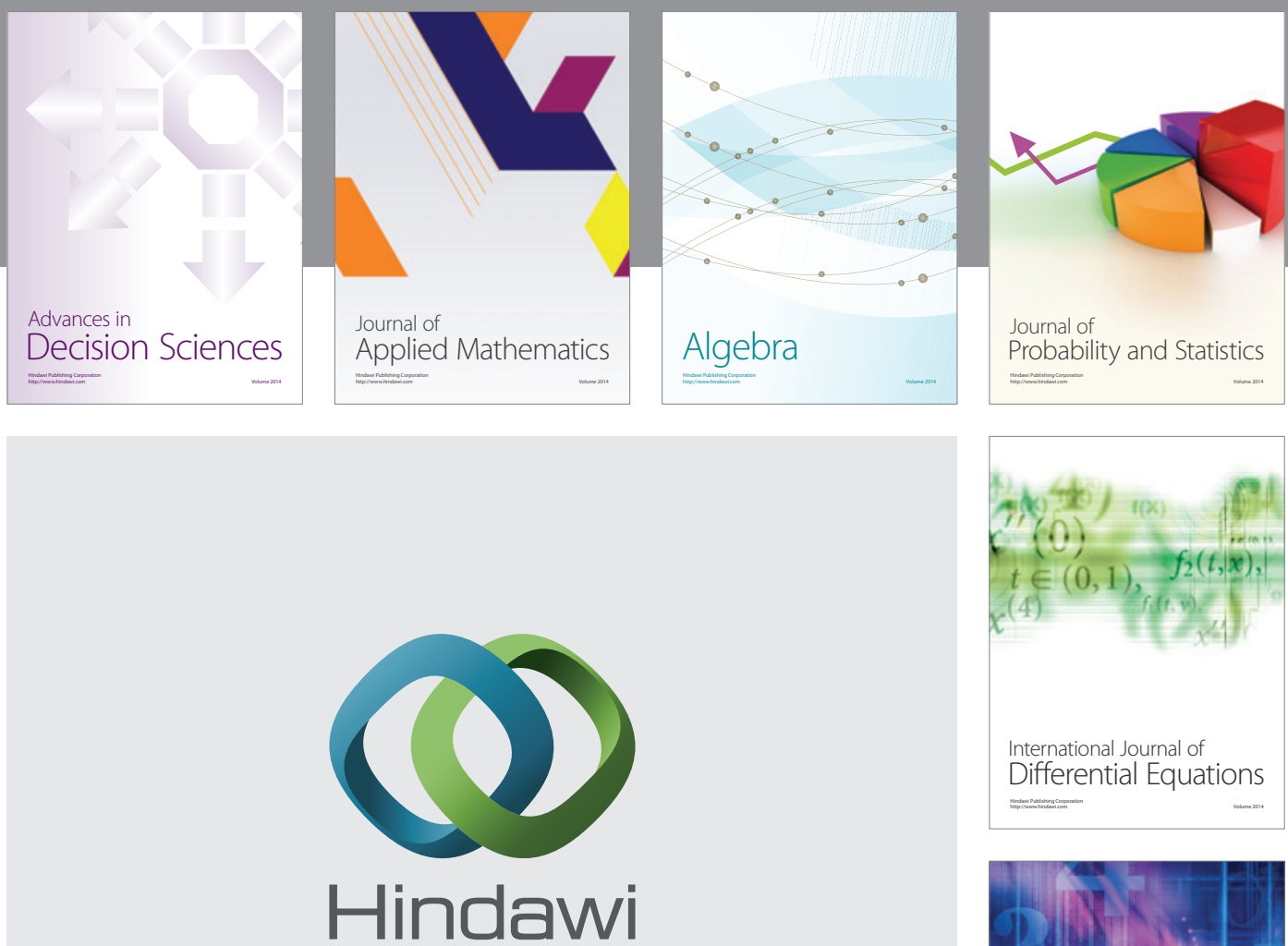

Submit your manuscripts at http://www.hindawi.com
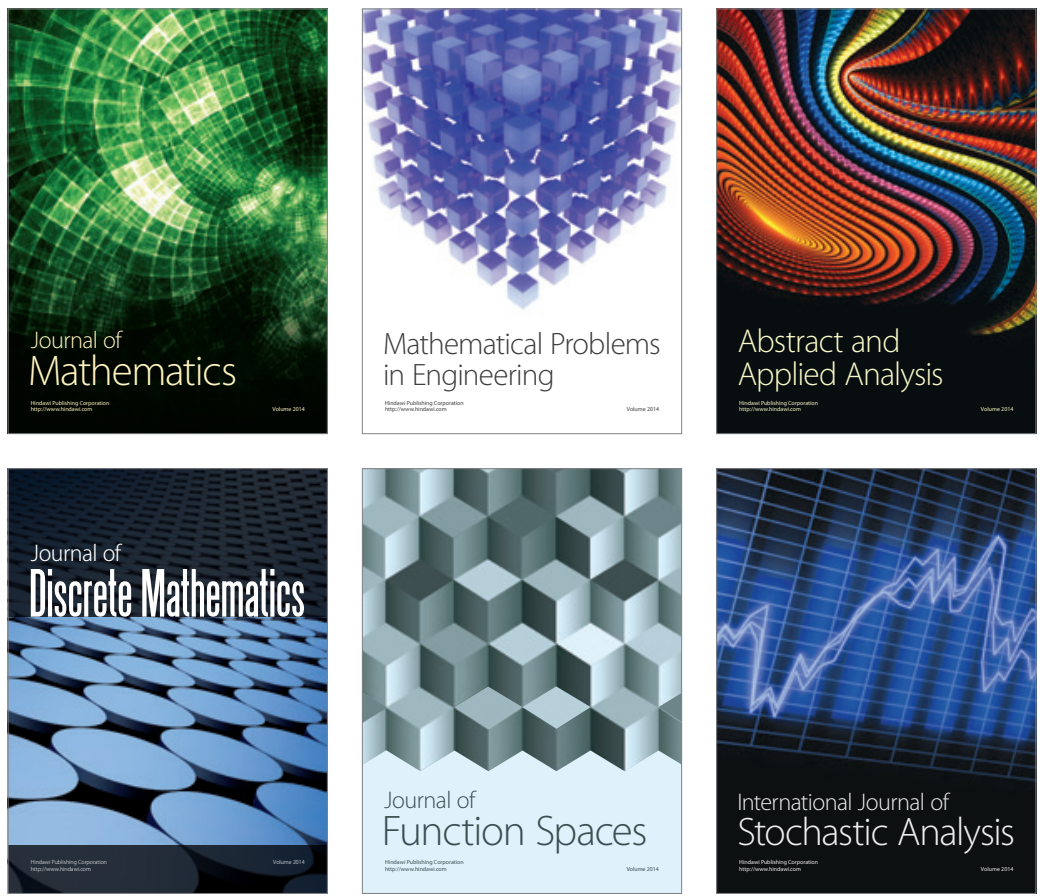

Journal of

Function Spaces

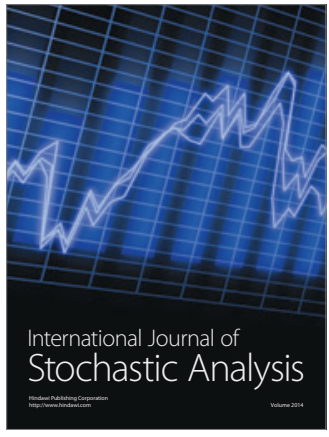

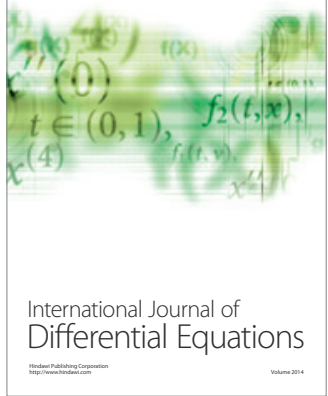
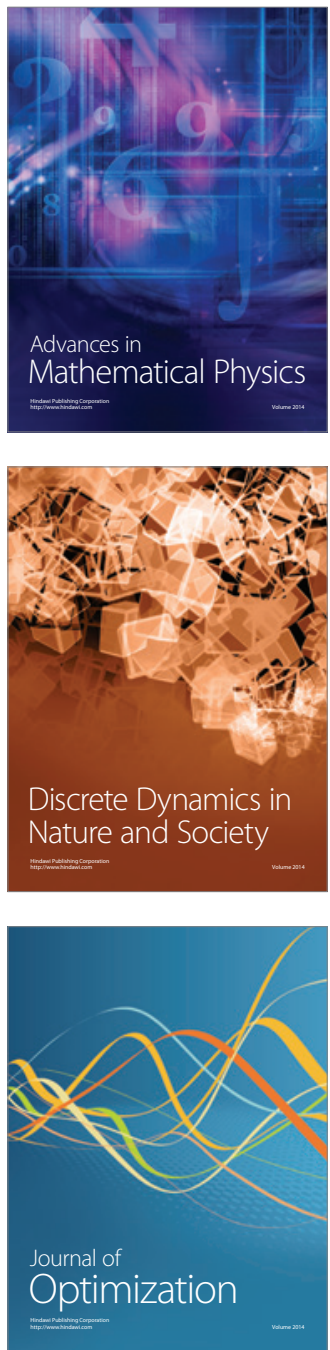